\title{
Public Crisis Management of Nonprofit Organizations
}

\author{
Liu Hong \\ School of Public Management, Yunnan University of Finance and Economics, Kunming, \\ P.R.China, \\ 650221 \\ (Email: 06liuhong@sina.com)
}

\begin{abstract}
Nonprofit organization is one of the social organizations. The nonprofit organizations in China have started to pay close attention to the public and play an important role in public crisis management. With the public crisis broke out constantly in recent years around the world, nonprofit organizations have become a majority force to handle public crisis with its social effects. However, due to the unstable of social circumstance, the internal and external factors of nonprofit organization, the public crisis management of nonprofit organizations still have various problems in China. This article analyzes the crisis management, the role and the problems of nonprofit organization, to explore the measures for nonprofit organizations to involve in public crisis management.
\end{abstract}

Keywords:Public Crisis Management, Nonprofit Organization, Problems, Measures

\section{Introduction}

The nonprofit organizations in China have started to pay close attention to the public and play an important role in public crisis management in recent years. Public crisis is caused by uncertainties due to internal and external environment to produce a serious threat to community interests of safety of a crisis situation or an emergency. It has characteristics like sudden, unpredictable, threatening and non-controlling. Public crises will seriously affect the normal social life and social order; make a great deal of harm to our society. Due to the limited nature of the functions of the government and the unpredictable nature of the crises will exacerbate the role of governmental "failure". Nonprofit organizations play an essential role in the public crisis management with immediate, efficient and flexible. But due to the limitations of its own characteristics, making it bear many risks in crisis management, theses in nonprofit organizations will generate a large number of obstacles. Therefore, the analysis of nonprofit organization in crisis management to explore the measures for nonprofit organization to involve in public crisis management is necessary.

\section{The ways of nonprofit organization involved in crisis management}

A nonprofit organization (NPO) is an organization that uses surplus revenues to achieve its goals rather than to distribute them as profit or dividends ${ }^{[1]}$. Some NPOs may also be a charity or service organization; they may be organized as a not-for-profit corporation .

\begin{tabular}{|c|c|}
\hline Number & Classification \\
\hline 1 & Community groups \\
\hline 2 & Economic groups \\
\hline 3 & Foundations \\
\hline 4 & Entities public service agencies \\
\hline 5 & Governmental organization \\
\hline \\
Tab.1. Classification of the Nonprofit \\
Organizations
\end{tabular}


There are 4 ways for nonprofit organization to involve in crisis management:

\subsection{Voluntary service}

The nonprofit organizations carry out various forms of voluntary service activities by organizing volunteers to join in. e.g. a voluntary service during the Wenchuan earthquake in 2008 and three steep of their service.

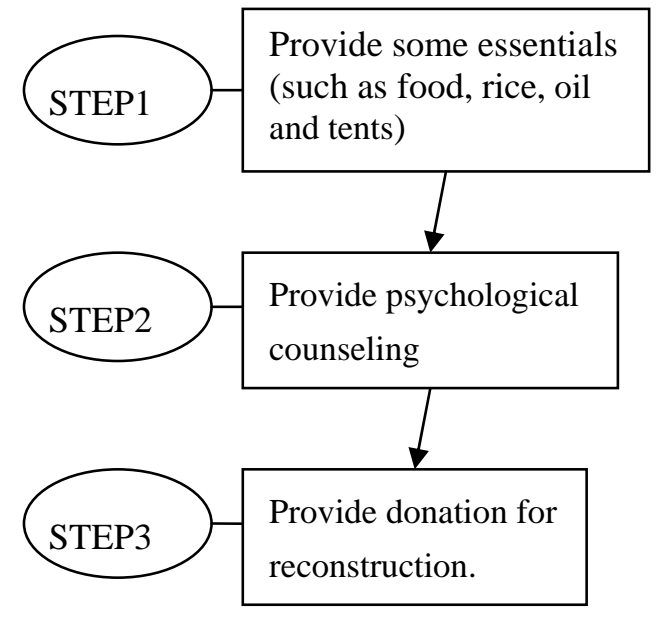

Fig.1. Three Steps of the Voluntary Service during the Earthquake

\subsection{Public service activities}

Play an essential role in society and public by using the same statement with other nonprofit organization to. There are numerous of public service activities in China, like the "Project of Hope" established by "China Youth Foundation" in order to help the teenagers in China grow better.

\subsection{Community service}

Community service is donated service or activity that is performed by someone or a group of people for the benefit of the public or its institutions [2]. Volunteers may provide community service; however, not everyone who provides community service is seen as a volunteer, because some people who provide community service are not doing it of their own free will.

\subsection{Social donation}

Nonprofit organizations play an important role in receiving social donation, especially after big natural disasters. For example, "the Red Cross Society of China” received nearly
199 billion RMB during the earthquake in Wenchuan.

\section{The strengths of nonprofit organization in crisis management}

There are 5 types of nonprofit organization in China: social organizations, financial organizations, foundations, public service institutions and governmental organizations. All of them have their strengths while the public crisis occurred.

\subsection{Warning before the public crisis}

As a social welfare organization, nonprofit organization has wide range of social information and base of membership. They have ability to warning the crisis because the take care of the weakness in our society with their professional knowledge and skills. This kind of ability will help them to catch useful information of the public crisis then provide warning to government and publics.

\subsection{Integration and coordination during the crisis}

The natures of nonprofit organizations determine the roles they play in crisis are significant.

First of all, they can initiate self-help and mutual aid before the professional emergency personnel arrived. The nonprofit organization can mobilize and integrate the social force; raise outside of the city government to deal with the resources of the new force of public crisis, the crisis can quickly mobilize material reserves into the crisis scene, saving the time of allocation of resources.

Secondly, the members of nonprofit organizations are mainly come from grassroots communities; therefore, the organization can use the power of society widely. Nonprofit organizations can use their own professional advantages to the causes and hazards to society to explain the crisis in a timely manner to inform the public about the developments, to help the public to eliminate the fear; on the other hand, nonprofit organizations can speak the sentiments of public opinion and the demand for timely feedback to the government to help the government to keep abreast of the actual situation, the information to improve the efficiency of handling the crisis.

Meanwhile, nonprofit organizations have the strengths in using their professional 
knowledge and skills to manage the public crisis.

\subsection{Constantly help after the crisis}

The other important role of nonprofit organization is to help the government deal with the reconstruction after crisis. Nonprofit organizations can provide aids in public services, rescue and rebuilding, psychological counseling etc.Crisis, community-based organizations, volunteer organizations and other nonprofit organizations to provide services crisis reconstruction and peace was restored, the nearest expand mutual rescue, but also from a deeper spiritual level up to help, to encourage the population affected by the crisis, the situation under control expanded to prevent causing a greater loss, the effective protection of victims of the fundamental interests of the masses and eliminate the instability in the society.

\section{Some problems of the crisis management in nonprofit organization}

There are various problems that the nonprofit organization facing during the public crisis management. The main problems including the lack of a complete system in legislation and regulation, the lack of credibility for nonprofit organization to participate in public affairs, lack of funds to attract professional staff and carry out crisis management, and poor coordination and communication of nonprofit organizations.

\subsection{Lack of a complete system}

In order to strengthen the legal management of the nonprofit organization, China has promulgated a number of legal, but the do not sound no longer meet the needs of modern society, especially the supervision of the nonprofit organization, powers and responsibilities of relevant laws and regulations should be improved. Inadequate laws and regulations make the nonprofit organizations have non legal basis in crisis management.

Nonprofit organizations implement dual management system in China. This kind of system is set a very high threshold for many non-profit organizations to establish which making a large number of active non-governmental and nonprofit organizations are difficult to not hit the public to play its due role.

\subsection{Lack of credibility}

Nonprofit organizations started late in China, the influence and penetration in the community is not large. The publics doubt about the legitimacy of the nonprofit organizations and motivation of participation in crisis management.

The social credibility for nonprofit organizations to participate in public affairs is reduced which lead to the lack of a broad social base and deep foundation of the people. When the crisis hit, more publics will pin their hopes on the government instead of nonprofit organizations.

\subsection{Lack of funds}

The funding sources of nonprofit organization including: government subsidies, private donations, service charges and foreign aid. In China, due to lack of donation environment, the main source of funding of nonprofit organizations are government subsidies and service charges. But there is a conflict between the service charges and public welfare and altruism of nonprofit organization, people questioned it. The lack of fund makes the nonprofit organizations difficult to allocate special funds into government's crisis management work. On the other hand, the lack of fund makes the nonprofit organizations can to provide competitive wages, and thus they have difficulties to attract professional and technical personnel to join them.

\subsection{Poor Coordination and Communication of Nonprofit Organization}

On the one hand, due to the lack of unified control mechanism for non-profit organization of manpower, materials and information resources, when faced with an emergency situation, the internal members of the non-profit organization is easy to get together, lack of communication between the non-profit organization, leading the blind and disorderly actions. On the other hand, in a public crisis management, non-profit organization acts as a complement of the government, to obey the government's command arrangements. Government departments and non-profit organizations often neglect or government executive order only to convey its decision-making, it touches on the lack of mutual communication 
between the non-profit organizations and government.

\section{Measures to solve the problems in nonprofit organizations}

The nonprofit organizations face a large sum of problems and difficulties in public crisis management. Although there are various internal and external factors of nonprofit organization to participate in public crisis, the measures to solve the problems are multiple and valid. According to the data and some investigations there are three ways (e.g. government, nonprofit organization and media) to solve them.

\subsection{The support of government}

Government should change the concept of actively expand cooperation with the nonprofit organizations to deal with the crisis. And nonprofit organizations should establish a crisis management mechanism.

Government should establish legal policy environment to protect and promote the growth of nonprofit organizations.

Government could change its restrictive measures on the nonprofit organizations.

\subsection{The own capacity building of nonprofit organizations}

The nonprofit organizations should strengthen the capacity in the construction of public crisis management system.

Strengthen the nonprofit organizations to address the public crisis capacity:

Improve the financing capacity of nonprofit organizations.

Establish its human resources system and the system of rules.

Strengthen the internal organization and management of construction, improve the level of profession.

\subsection{Publicity in the media}

Positive publicity social media to nonprofit organization, to expand the understanding of the Task Force on nonprofit organization and channels of supervision to increase the transparency of nonprofit organizations, especially related funds toward transparency, dispel public misunderstanding, increase the public confidence of nonprofit organizations.

\section{Conclusion}

With the public crisis broke out constantly in recent years around the world, nonprofit organizations have become a majority force to handle public crisis with its social effects. Public crisis is caused by uncertainties due to internal and external environment to produce a serious threat to community interests of safety of a crisis situation or an emergency. The nonprofit organizations in China have started to pay close attention to the public and play an important role in public crisis management. However, due to the unstable of social circumstance, the internal and external factors of nonprofit organization, the public crisis management of nonprofit organizations still have various problems. Through the analysis of the ways that nonprofit organization involved in public crisis, the role and the problems of nonprofit organization facing in recent years this article explore some measures for nonprofit organizations to solve the problems and difficulties during the manage of public crisis. Due to the limited nature of the functions of the government and the unpredictable nature of the crises will exacerbate the role of governmental "failure". Nonprofit organizations play an essential role in the public crisis management with immediate, efficient and flexible. But due to the limitations of its own characteristics, making it bear many risks in crisis management, theses in nonprofit organizations will generate a large number of obstacles.

In short, the public crisis has the characteristics of uncertainty, the dangers of extensive and unconventional such public crisis prevention. mitigation and dissolution of government and non-profit organizations, including the social aspects of coordination and efforts. Enhance the risk aversion ability of nonprofit organizations in the public crisis is an important means to carry out its functions. 


\section{References}

[1] The Nonprofit Handbook: Everything You Need to Know to Start and Run Your Nonprofit Organization (Paperback), Gary M. Grobman, White Hat Communications, 2008.

[2] "community service". Memidex/WordNet Dictionary. Retrieved 2011-07-25

[3] Snyder, Gary R., Nonprofits: On the Brink: How Nonprofits have lost their way and some essentials to bring them back, 2006.

[4] P. Hartigan, 2006, 'It's about people, not profits', Business Strategy Review, Winter 2006

[5] James, Erika; Lynn Perry Wooten (2010). "Why Discrimination Lawsuits Are a Noteworthy Crisis". Leading Under Pressure. Routledge Academic

[6] Coombs, W. T. (1999). Ongoing crisis communication: Planning, managing, and responding. Thousand Oaks, CA: Sage
[7] Hellsloot, I. (2007). "Review of "The politics of crisis management: Public leadership under pressure" by A. Boin, P. Hart, E. Stern and B. Sundelius". Journal of Contingencies and Crisis Management 15 (3): 168-169. DOI:10.1111/j.1468-5973.2007.00519.x

[8] Seeger, M. W.; Sellnow, T. L., \& Ulmer, R. R. (1998). "Communication, organization and crisis". Communication Yearbook 21: 231-275

[9] Lerbinger, O. (1997). The crisis manager: Facing risk and responsibility. Mahwah, NJ: Erlbaum

[10] Zhang Xiaojun, Qi Haili. Non-profit organizations to participate in public crisis management [J]. XUEHUI, 2007(2): 20-33 